\title{
Pobreza en la producción de conocimiento y la formación profesional del Trabajo Social en Brasil
}

\section{Poverty in the production of knowledge and Professional Training of Social Work in Brazil}

Eliana Andrade-da-Silva

Universidade Federal do Rio Grande do Norte, Natal, Brasil

$\triangle$ andradelili@yahoo.com.br

(i) https://orcid.org/0000-0002-9244-4770

\section{RESUMEN}

Objetivo. El presente artículo tiene la intención de problematizar el debate sobre la categoría pobreza en la producción de conocimiento y en la formación profesional del Trabajador Social. Método. Este artículo fue elaborado a partir de una investigación documentaria y bibliográfica. Resultados. Los resultados apuntan al predominio de abordajes teóricos sobre la categoría pobreza en el ámbito de Trabajo Social a partir de un prisma de totalidad, en el cual las relaciones vigentes de la sociedad desencadenan un proceso de desigualdades sociales donde conviven contradictoriamente abundancia y miseria. En este sentido, la investigación indica la existencia de algunos consensos y disensos entre los autores con respecto a la necesidad de insertar en la formación profesional del Trabajador Social el análisis sobre los orígenes y expresiones del fenómeno pobreza. Conclusiones. Se concluye que, aunque haya en el ámbito de formación profesional el predominio de concepciones de pobreza afiliadas a la tradición marxista, coexisten concepciones de pobreza vinculadas a las matrices teórico-metodológicas oponentes, las cuales traen críticas a la perspectiva crítico-dialéctica. Así, se configura un cuadro analítico marcado por polémicas y embates teórico metodológicas relevantes, resultando en la producción de nuevos estudios e investigaciones en el área de Trabajo Social.

Palabras clave: Pobreza; producción de conocimiento; Trabajo Social. 


\section{ABSTRACT}

Objective. The present article intends to problematize the debate on the category poverty in the production of knowledge and in the professional training of the Social Worker. Method. This article is based on documentary and bibliographical research. Results. The results point to the predominance of theoretical approaches on the category poverty in the scope of Social Work from a prism of totality, in which the current relations of society unleash a process of social inequalities where abundance and misery coexist contradictorily. In this sense, the investigation indicates the existence of some consensus and dissent among the authors with respect to the need to insert in the professional formation of the Social Worker the analysis on the origins and expressions of the phenomenon Poverty. Conclusions. It is concluded that, although there is in the scope of professional formation the predominance of conceptions of poverty affiliated to the Marxist tradition, there coexist conceptions of poverty linked to the opposing theoretical-methodological matrices, which bring criticisms to the critical-dialectic perspective. Thus, an analytical framework marked by polemics and relevant theoretical and methodological attacks is formed, resulting in the production of new studies and research in the area of Social Work.

Keywords: Poverty; production of knowledge; Social Work.

\section{INTRODUCCIÓN}

En Brasil los estudios acerca de la pobreza se han ampliado en las últimas décadas. En ese contexto, renombrados intelectuales se han centrado en el análisis de ese fenómeno, de manera que este tema se constituye como preocupación de diversas áreas de saber cómo: economía, educación, trabajo social, entre otras profesiones, que han dedicado considerable espacio para discusiones acerca de dicho fenómeno.

En la particularidad del Trabajo Social, la categoría pobreza encuentra lugar de destaque en el ámbito de las investigaciones y también en el ámbito de la intervención profesional en las instituciones sociales. A medida que los debates en torno a la pobreza en el Servicio Social se amplían, se suscitan polémicas teórico-metodológicas en el campo de los paradigmas de explicación de la realidad.

En el ámbito de la formación profesional del Asistente Social en Brasil, el tema "pobreza" se inserta en el Núcleo de Fundamentos de la Particularidad de la Formación Socio Histórica de la sociedad brasileña e involucra cuestiones relativas a los patrones de desarrollo social y económico del capitalismo en la realidad del país. Históricamente, predominan en el ámbito del trabajo social brasileño análisis filiados a una tradición intelectual crítica dialéctica. Sin embargo, otros enfoques teóricos se han presentado en el debate, especialmente aquellos originados por las propuestas del Banco Mundial.

En una óptica tradicional, la pobreza ha sido concebida como carencia de ingresos y como obstáculo al desarrollo, debiendo así ser erradicada y combatida. En esta perspectiva, su medición está ligada sobre todo a la renta per capta de los individuos o familias y su capacidad de consumo 
Sin embargo, el análisis del tema "pobreza" demanda la articulación de diversos factores que exceden los ingresos individuales y el poder de consumo de las unidades familiares. En ese sentido, se parte del presupuesto de que el entendimiento de la temática requiere un abordaje multifactorial. En términos analíticos, se apunta que la pobreza no se reduce a condiciones materiales y puede considerarse una categoría de gran complejidad teórica. Se recurre a las reflexiones de Yasbek (2012) que inicia sus análisis afirmando que la pobreza se revela como una cara del descarte de mano de obra, resultante de las formas de expansión de la economía capitalista.

De esta forma, la pobreza puede ser comprendida desde una perspectiva totalizante, a través de la cual se expresa como manifestación de la Cuestión Social, generada por las relaciones vigentes en la sociedad capitalista marcadamente desigual, donde conviven contradictoriamente abundancia y miseria (Silva, 2016).

En el caso del Trabajo social, la pobreza se constituye como una temática presente en las elaboraciones de sus estudiosos, aunque no se constituya como campo específico de estudios. La cuestión de la pobreza se encuentra articulada al debate de la Cuestión Social, de las políticas sociales y de la desigualdad social, provenientes de la sociabilidad capitalista.

Por lo tanto, sea en el ámbito de las investigaciones, sea en el ámbito de la actuación de los Trabajadoras sociales, el debate de la pobreza se hace presente, teniendo en cuenta que profesionales de Trabajo Social actúan ampliamente en las políticas sociales de enfrentamiento a la pobreza a través de la Política Nacional de Asistencia Social (PNAS) ${ }^{1}$ ), particularmente en el escenario de los Centros de Referencia en Asistencia Social (CRAS) y en los Centros de Referencia Especializados en Asistencia Social (CREAS).

\section{MÉTODO}

Es en este contexto que el presente artículo se constituye como una problematización acerca del debate de la categoría pobreza en la formación profesional del Asistente Social en Brasil y en la producción de conocimientos en el área. En términos metodológicos, este artículo es el resultado de una investigación bibliográfica, realizada en las producciones de los principales investigadores brasileños sobre el fenómeno de la pobreza, especialmente Carmelita Yasbek, Vera Telles, Luana Siqueira.

La investigación también analizó los principales ejes rectores de la formación profesional de los trabajadores sociales en Brasil, a través de la encuesta de las producciones teóricas sobre el tema, así como sobre las Directrices curriculares para la formación de trabajadores sociales organizadas por la Asociación Brasileña de Estudios e Investigación en Trabajo Social (ABEPSS). Aliado a esto, se realizó una investigación documental sobre la legislación sobre asistencia social en Brasil, en particular sobre la Ley Orgánica de Asistencia Social (LOAS) y la Política Nacional de Asistencia Social (PNAS).

1 La política de Asistencia Social se destina, por lo tanto, "al enfrentamiento de la pobreza, la garantía de los mínimos sociales, a la provisión de las condiciones para atender contingencias sociales a la universalización de los derechos sociales". (LOAS, 1993: 155). 
La investigación se delimitó en un período de análisis de los años entre 2004 y 2018, considerando que, a partir de este momento, la pobreza se vuelve central en la agenda del gobierno y la producción científica del trabajo social sobre el tema comienza un nuevo ciclo. El análisis de los datos obtenidos fue guiado por el método dialéctico materialista histórico.

En este artículo se defiende la tesis que el debate de la pobreza se profundiza a partir de los años 2004, cuando la Promulgación de la Política Nacional de Asistencia Social (PNAS) trae a la luz polémicas teórico-metodológicas en torno a las concepciones de pobreza que se expresan en la formación y en la producción de conocimientos en el Trabajo Social brasileño. Es fundamental destacar que la promulgación de esta política social amplía significativamente el mercado de trabajo para las Trabajadoras Sociales, resultando no solo en nuevas inserciones profesionales, sino en el embate teórico sobre las concepciones de pobreza, expresando polémicas en la producción de estudios y en las investigaciones en el área de Trabajo social.

En resumen, el artículo presentado aquí puede contribuir a los estudios sobre la relación entre la pobreza, la producción de conocimiento y la formación del trabajador social actual, considerando que este trabajo realiza un esfuerzo de sistematización teórico que puede ser una fuente de investigación para futuros estudios.

\section{RESULTADOS}

La categoría pobreza y su relación con la formación profesional del Asistente Social. El análisis sobre pobreza y su relación con la formación profesional del Asistente Social brasileño requiere situar al lector sobre el proceso que da origen al actual proyecto de formación académica profesional en curso en el país. En términos históricos, las grandes transformaciones de carácter teórico, metodológico, ético y operativo de la profesión remiten al proceso Reconceptualización ${ }^{2}$ del Trabajo Social. Este proceso culmina en una revisión crítica sobre las bases teórico-prácticas del Trabajo Social a partir de los años 1960, pero es en el desarrollo de la década de 1970 que estas modificaciones se inician, radicalizándose en la década de 1980 . Los reflejos de las modificaciones operadas por la Reconceptualización se hacen sentir también en el ámbito de la formación profesional, lo que contribuye a que haya una crítica a sus Fundamentos a lo largo de los años 1980 y 1990 y resulte también en la revisión de su Proyecto de Formación Profesional en la década de 1990.

Así, como uno de los resultados del movimiento de Renovación del Trabajo Social se destaca la revisión curricular que ocurre en la década de 1990, la cual da origen a las Directrices Curriculares para el Curso de Trabajo Social, aprobadas por el Ministerio de Educación y Cultura en el año 1996 y en vigor hasta el presente momento. Un marco en este proceso de reformulación de las Directrices Curriculares es la afirmación del estatuto profesional del Trabajo Social definido como una especialización del trabajo colectivo en los marcos del capitalismo monopolista (Iamamoto, 2008).

2 El Movimiento de Reconceptualización consistió en una revisión crítica de las bases teóricas, metodológicas, éticas y políticas del Trabajo Social en Brasil. Este movimiento se inició en la segunda mitad de la década de 1960 y se extendió hasta la década de 1980 y fue fundamental para construir las bases contemporáneas de la profesión en la particularidad brasileña. Para una profundización de este tema consultar NETTO, J. P. Ditadura e Serviço Social: uma análise do serviço Social no Brasil pós- 64. - 7. Ed. SP: Cortez, 2004. 
Andrade-da-Silva - Pobreza en la producción de conocimiento y la formación profesional del Trabajo Social en Brasil

También, es marcante en estas nuevas Directrices la estructuración de tres Núcleos de Fundamentación: a) Núcleo de fundamentación teórico-histórica de las configuraciones socioeconómicas, culturales, políticas y teóricas del ser social; b) Núcleo de fundamentación de la particularidad de la formación sociohistórica brasileña insertada en la división sociotécnica del trabajo; c) Núcleo de Motivación del trabajo Profesional: (ABESS/CEDEPSS, 1996).

Tomando como referencia estos parámetros es posible señalar que, en el ámbito de la formación profesional del Asistente Social, el debate sobre la categoría pobreza se inserta en el Núcleo de Fundamentos de la Particularidad de la Formación Socio Histórica de la sociedad brasileña ${ }^{3}$ el cual "remite al conocimiento de la constitución económica, social política y cultural de la sociedad brasileña, en su configuración dependiente, urbanoindustrial en las diversidades regionales, articulada con el análisis de la cuestión agraria, como elemento fundamental de la particularidad histórica nacional" (ABESS/CEDEPSS, 1996, p. 168).

Este debate incluye el análisis de cuestiones relativas a los patrones de desarrollo capitalista en Brasil y sus impactos sobre el Estado y la Sociedad y se centra en cuestiones tales como: las desigualdades sociales, la diferenciación de clase y la exclusión social y, consecuentemente, sobre la cuestión de la pobreza. Por lo tanto, incluye un conjunto de elementos relativos a la reproducción histórica de la pobreza y de la desigualdad social y de las formas de su enfrentamiento en la sociedad contemporánea. Así, el proyecto de formación se orienta en la perspectiva de formar un perfil profesional capaz de aprehender las macro determinaciones que rigen la sociedad, así como sus expresiones concretas en la vida de los sujetos. Por lo tanto, el perfil a ser formado sigue la siguiente orientación:

Que sea dotado de formación intelectual y cultural generalista y crítica, competente en su área de desempeño, con capacidad de inserción creativa y propositiva en el conjunto de las relaciones sociales y en el mercado de trabajo y comprometido con los valores y principios orientadores del Código de Ética del Asiste Social (Guerra, 2013, p. 249).

Desde este punto de vista, la formación profesional señala como una perspectiva primordial un análisis riguroso de los aspectos teóricos, históricos y metodológicos de la realidad social, anclados en una teoría social crítica y en un método que permite un análisis histórico y la totalidad de las relaciones sociales. Un hito en este proceso de reformulación de las Directrices Curriculares es la afirmación del estatus profesional del Trabajo Social definido como una especialización del trabajo colectivo en el marco del capitalismo monopolista (Iamamoto, 2008). Este período también resultó en la apropiación de la categoría analítica "Cuestión social" que, según Iamamoto (2008):

Son solo las expresiones del proceso de formación y desarrollo de la clase trabajadora y su entrada en el escenario político de la sociedad, exigiendo su reconocimiento como clase por la comunidad empresarial y el estado. Es la manifestación, en la vida cotidiana de la vida social, de la contradicción entre el proletariado y la burguesía, lo que requiere otros tipos de intervención, más allá de la caridad y la represión (p. 168).

3 Aunque la discusión sobre la pobreza esté, a priori, insertada en el Núcleo de Fundamentos de la particularidad de la Formación Sociohistórica de la Sociedad Brasileña, no significa decir que este debate no necesite aportes provenientes del Núcleo de Fundamentación Teórico-histórica de las Configuraciones Socioeconómicas, Culturales, Políticas y Teóricas del Ser Social. 
Desde este entendimiento, la Cuestión Social se reconoce ahora como un elemento básico para comprender las determinaciones que resultan en el surgimiento de la profesión en la sociedad capitalista, así como convertirse en uno de los aspectos centrales de los fundamentos de la formación profesional, para calificar a los profesionales. Para su comprensión y resolución (Iamamoto, 2008). En este sentido, es esencial retomar la concepción de Fundamentos que se encuentra dentro de las Guías Curriculares que brindan apoyo teórico metodológico para la formación y práctica profesional del Trabajador Social. De acuerdo con Guerra (2004) para conceptualizar los Fundamentos es concebirlos:

Como las bases materiales que lo sostienen, la base, sus determinaciones, la lógica constitutiva y constitutiva de los procesos y prácticas sociales. El procedimiento de ir a las fundaciones es el movimiento mismo de la razón que busca comprender las bases ontológicas que subyacen a los procesos y prácticas sociales y profesionales ( $p$. 07).

Por lo tanto, es sobre estas bases que la formación profesional del trabajador social se basa en la revelación de determinaciones sociales que ayudan a entender la profesión como un tipo de especialización del trabajo colectivo en la división social y técnica del trabajo (Iamamoto, 1982). Por lo tanto, la formación de profesionales se basa en una perspectiva de integridad que se expresa en una formación generalista que permite conectar la particularidad de la profesión del Trabajo Social con el movimiento de reproducción social, proporcionando a las profesionales habilidades teóricas, éticas, políticas y técnicas, para ser implementado en el mercado laboral.

En ese sentido, la temática pobreza es un aspecto relevante que observar en la formación profesional, sobre todo en un contexto en el que hay una ampliación de las discusiones acerca de la pobreza en la sociedad brasileña. Las concepciones de pobreza están presentes en el discurso oficial (gubernamental), en la producción de conocimientos y en la visión de los profesionales que actúan en las acciones de enfrentamiento a la pobreza ${ }^{4}$.

El fenómeno de la pobreza es considerado como una marca relevante de la sociedad brasileña moderna y sus expresiones han suscitado interés de las agencias internacionales, de los gobiernos y de los intelectuales de distintos matices, los cuales se han ocupado del análisis de este fenómeno en sus elaboraciones teóricas.

En virtud de las expresiones cada vez más agudas de la pobreza, el debate sobre las formas de enfrentarla se amplía en Brasil, sobre todo en el contexto de crisis económica. En la realidad brasileña, los datos apuntan a la existencia de una brutal desigualdad social y económica, ya que el $10 \%$ considerado más rico posee el $75 \%$ de la riqueza total, mientras que el $90 \%$ más pobre se queda con apenas el $25 \%$ de la riqueza producida. Estos datos acompañan un movimiento más general de concentración de renta y riqueza en América Latina, ya que es constatado que más del $40 \%$ de la población es pobre y que el $15 \%$ al $20 \%$ de ella son considerados indigentes.

En términos históricos la pobreza se constituye como un fenómeno persistente en la sociedad brasileña, la cual experimentó distintos procesos políticos, económicos y

$4 \quad$ En una investigación realizada por Silva \& Domingos (2017) se levantaron las concepciones de pobreza que orientan la actuación de los profesionales en el Programa Bolsa Familia en Rio Grande do Norte. Este estudio fue realizado entre los años 2015 y 2017 y tuvo como objeto "las representaciones sociales de los cursistas de la Iniciativa Educación, Pobreza y Desigualdad Social sobre la pobreza". 
sociales, pero no logró superar esta problemática que se actualiza y, al mismo tiempo, recupera rastros del pasado. En este sentido:

La pobreza contemporánea arma un nuevo campo de cuestiones al desbordar de los lugares en los que estuvo configurada 'desde siempre': en las franjas del mercado de trabajo, en el submundo de la economía informal, en los confines del mundo rural, en un Nordeste de pesada herencia oligárquica, en todo lo demás, en fin, que proporcionaba (y aún proporciona) las evidencias de la lógica excluyente propia de las circunstancias históricas que presidieron la entrada del país en el mundo capitalista (Telles, 2013, p.16).

Aunque los ingresos no sean el único factor de medición de la pobreza, sigue siendo un indicador relevante. Así, el análisis de las diferencias de ingresos entre países en el mundo apunta a una caída inédita de la desigualdad mundial en el último siglo, proveniente del crecimiento económico de China e India, que albergan a la mitad de los pobres del mundo. La desigualdad interna de los países llamados "desarrollados", después de la crisis de 2008, sigue un movimiento inverso apuntando hacia el aumento de las desigualdades.

De acuerdo con los análisis de Silva (2016) el entendimiento de la pobreza debe partir de una perspectiva totalizante:

Comprendiéndola como manifestación de la cuestión social. De esta forma, como expresión de las relaciones vigentes en la sociedad marcada por un patrón de desarrollo capitalista, extremadamente desigual, en que conviven acumulación y miseria (p. 93).

Se parte del presupuesto que una clave analítica para la comprensión del fenómeno de la pobreza se encuentra en la trama de la constitución de la Cuestión Social y sus determinaciones económicas, sociales e históricas. Tal cuestión puede ser comprendida a través de sus conexiones con las configuraciones asumidas por el trabajo y por los proyectos ideológicos y económicos en presencia en la sociedad brasileña. La Cuestión Social se constituye como parte de la sociabilidad en la era del capital y sus expresiones van mucho más allá de la pobreza, la miseria y la exclusión. Es decir, la cuestión social "condensa la banalización de lo humano, que atesta la radicalidad de la alienación y la invisibilidad del trabajo social -y de los sujetos que lo realizan- en la era del capital fetiche" (Iamamoto, 2008, p. 147).

En la realidad brasileña, las expresiones más relevantes de la Cuestión Social en la escena contemporánea pueden ser identificadas a través de la exclusión de amplios sectores del mercado formal de trabajo, de la poca o ninguna cobertura de derechos sociales y laborales, del desempleo de carácter estructural, de la falta de acceso a la salud, de la baja cualificación profesional entre otros factores presentes, principalmente en la vida de las clases subalternas.

En tal contexto emergen los denominados pobres. Considerados en nuestros análisis como resultados concretos de relaciones sociales desiguales, los cuales experimentan las marcas de la pobreza y son afectados por la reproducción de las desigualdades sociales y por las contradicciones capitalistas en varios niveles: económico, político, social. 
En la particularidad brasileña las formas de enfrentamiento de la pobreza se han dado a través de la tríada: políticas de inclusión, de cuotas y de transferencia de renta. La estrategia privilegiada de combate a la pobreza adoptada por el gobierno brasileño, sobre todo en la última década, se ha dado a través de los Programas de Transferencia de Renta (PTR's) ${ }^{5}$. Estos programas encuentran una trayectoria de desarrollo que se modifica a partir de $2003^{6}$ siendo considerado como el quinto momento de esta trayectoria resultando en cambios significativos en los PTR's, sobre todo, en la unificación de los programas culminando en la creación del Bolsa Familia. El año 2011 inaugura el sexto momento de los PTR's orientado por la erradicación de la miseria. Es decir, es por la mediación de la acción del Estado a través de las políticas sociales que la cuestión de la pobreza es enfrentada.

En ese movimiento se encuentra un punto de convergencia entre el trabajo social y la temática pobreza. Es decir: es a través de las políticas sociales de enfrentamiento a la pobreza (sobre todo de los PTR's) que los profesionales de trabajo social se acercan a esta realidad al insertarse en los programas, proyectos y acciones dirigidas a su enfrentamiento. Las trabajadoras sociales generalmente se encuentran insertados en la Política Nacional de Asistencia Social (PNAS) especialmente en el escenario de los Centros de Referencia en Asistencia Social (CRAS) y en los Centros de Referencia Especializados en Asistencia Social (CREAS)

Por su parte, esta inserción plantea desafíos y demandas para la Formación Profesional en el Trabajo Social que se traducen en la preparación de los futuros profesionales para actuar en las expresiones de la Cuestión Social que se materializan en la pobreza y en sus consecuencias en la vida de los sujetos sociales.

Así, para efecto de aprehensión de las concepciones de pobreza se analiza el discurso gubernamental sobre pobreza presente los marcos regulatorios, destacándose la Ley Orgánica da Asistencia social (Ley n. 8742/93), para la Política Nacional de Asistencia Social (Resolución CNAS n. 145/04), Resolución CNAS n. 130/05 Norma Operativa Básica de SUAS y la Ley n. 10.836/04 del Programa Bolsa familiar.

En el marco de la PNAS la concepción de pobreza se asocia a la cuestión de la exclusión social. Es decir, la pobreza es:

Asociada a la desigualdad y la perversa concentración de ingresos, se revela en una dimensión más compleja: la exclusión social. El término exclusión social se confunde comúnmente, con desigualdad, miseria, indigencia, pobreza (relativa o absoluta), aportación social, entre otras. Naturalmente existen diferencias y semejanzas entre algunos de estos conceptos, aunque no existe consenso entre los diversos autores que se dedican al tema. Sin embargo, a diferencia de la pobreza, la miseria, la desigualdad e indigencia que son situaciones, la exclusión social es un proceso que puede llevar a acentuar la desigualdad y la pobreza, y, como tal, se presenta en el tiempo y en el espacio. (Brasil, 2004, p. 203).

5 Los PTR's se consienten "como mecanismos privilegiados de política social en América Latina y el Caribe, cuyos rasgos principales son el público objetivo, constituido por familias pobres y extremadamente pobres, y el establecimiento de condicionalidades (corresponsabilidades), asociados al incentivo de la demanda y oferta de trabajos sociales". (SILVA, 2016, p. 97). En Brasil esta modalidad de acción comienza a partir de 1995 en las ciudades de Campinas, Ribeirão Preto y Santos en el estado de São Paulo. El Bolsa Familia es una modalidad de PTR implantada en Brasil a partir de 2003.

6 Se encuentra en Silva (2016) un balazo crítico acerca de los Programas de Transferencia de Renta en Brasil en Uruguay y también en Argentina. La controversia que involucra esta opción está ligada al hecho de ser la transferencia de renta implementada en detrimento de las políticas estructurantes, con ello, se percibe que hubo avances en los sectores más empobrecidos de la sociedad, sin embargo, Brasil todavía está entre los 12 países con las mayores tasas de desigualdad del mundo. 
Andrade-da-Silva - Pobreza en la producción de conocimiento y la formación profesional del Trabajo Social en Brasil

Es posible observar en la PNAS una tendencia a asociar pobreza con exclusión social. En el discurso gubernamental la pobreza no está determinada por las desigualdades, sino que es solo "asociada" a esta. Pobreza también aparece con algo "asociado" a la concentración de la renta. No es posible identificar en esta perspectiva los elementos determinantes, sea de la pobreza, sea de la desigualdad, sea de la exclusión social. Se revela también la constatación de que no hay consensos entre los conceptos, pero no hay la adopción clara de una concepción de pobreza. En realidad, queda explícito que la categoría exclusión social es la más relevante, siendo el motor del agravamiento de la desigualdad y de la pobreza.

La importancia del análisis de la concepción de pobreza presente en las Directrices de la PNAS está relacionada a una fuerte influencia que esta concepción tiene en la formación de la visión de mundo de los profesionales del Trabajo Social que actúan en las políticas sociales. Pero esta influencia va más allá y también se verifica en la producción de conocimiento académico realizada por los intelectuales del área como se observa en el ítem seguir.

Las concepciones de pobreza en la producción de conocimiento en el ámbito del Trabajo Social. La profesión de Trabajo Social desde su origen se ha enfrentado al fenómeno de la pobreza. Así, la profesión se ha dedicado al entendimiento del fenómeno de la pobreza y de las formas de respuesta profesional en la perspectiva de enfrentamiento de dicho fenómeno. Este debate ha sido tematizado por la categoría de trabajadoras sociales de diversas formas y ha ocupado posición relevante en el temario profesional, sobre todo en los orígenes de la profesión, durante su proceso de profesionalización ${ }^{7}$ en Brasil a partir de la década de 1930. En este período los resultados de las acciones del trabajo social se materializaban en la:

Atención a las carencias más urgentes del gran número de pobres ya las necesidades más inmediatas del trabajador y su familia, producían un efecto social muy importante, reduciendo las manifestaciones aparentes de los problemas y fortaleciendo la ilusión de que el Estado tenía un paternal interés por el ciudadano (Martinelli, 2011, p. 126).

El debate sobre la pobreza en el trabajo Social remite principalmente a la reflexión de las problemáticas que este fenómeno genera y que se traducen en demandas profesionales para los trabajadores sociales. Otro aspecto que fortalece la temática de la pobreza en el trabajo social es el hecho de que la mayoría de los usuarios de los servicios prestados por los trabajadores sociales es considerada pobre.

Esto puesto, se puede considerar que varias son las concepciones de pobreza que permean el ideario del Trabajo Social. Las concepciones más ampliamente divulgadas son influenciadas por la de conocimiento académico realizado por los intelectuales del área en el tema de la pobreza y también por las legislaciones que se constituyen como marcos de algunas políticas sociales especialmente en el área de la asistencia social.

$7 \quad$ Las encíclicas Rerum Novarum (1891) y Quadragésimo Anno (1929) operaron una influencia decisiva en la formación profesional de los trabajadores sociales que ofrecían todo un conjunto de informaciones y concepciones acerca de la sociedad, la política, la economía, así como propuestas de enfrentamiento de la llamada cuestión social. 
En el levantamiento de las concepciones de pobreza que influencian la construcción de las visiones de mundo de la categoría de los trabajadores sociales, Siqueira (2013) nos apunta siete ejes. Estas concepciones fueron sistematizadas en la perspectiva de indicar las tendencias expresivas en la literatura profesional y los respectivos formuladores:

a) Pobreza asociada a las necesidades y carencias: El análisis se centra en la dimensión económica de la pobreza, la cual se expresa a través de la carencia. El pobre es visto como necesitado o carente (Aldaíza Sposati);

b) Pobreza asociada a la subalternidad y a la exclusión: El análisis asocia la pobreza a la subalternidad y supone relaciones de desigualdad entre dominantes y subalternos (Carmelita Yasbek);

c) Pobreza asociada a la noción de popular: Pobreza es entendida como manifestación de la Cuestión Social y como expresión de las relaciones vigentes donde la miseria y la acumulación conviven. En estos análisis los pobres se revelan como resultado de las relaciones sociales (Maria Ozanira Silva);

d) Pobreza y ciudadanía invertida: El análisis se centra en la relación entre pobreza y ciudadanía en la que aparece el concepto de ciudadanía en Thomas Humprey Marshall. La ciudadanía como conjunto de derechos. Por lo tanto, la falta de derechos revela una "no-ciudadanía" (Sônia Fleury);

e) Pobreza asociada a la noción de riesgo y vulnerabilidad: Este análisis tiene su origen en las áreas de geografía, urbanismo, demografía y salud. Se trata de una concepción que vincula la pobreza con contextos de riesgo y vulnerabilidad social. En tal contexto, el pobre es alguien en desventaja social. Elaboración del Banco Mundial y Cepal ha defendido esta visión (Robert Castel, Boaventura de Souza Santos e Antonny Giddens);

f) Pobreza asociada a la ausencia de poder: La pobreza es comprendida como ausencia de poder o fragilidad. Así, el empoderamiento sería una alternativa para la resolución de problemas sociales (Amartya Sen, Deepa Narayan, Boaventura de Souza Santos, Vicente Faleiros);

g) Pobreza asociada a la Ley general de la acumulación: En esta noción la pobreza está articulada a la desigualdad social y estos se constituyen como fenómenos generados por el capitalismo, pasibles de explicación a través de la Ley General de la acumulación (Karl Marx).

En posesión de la sistematización realizada por Souza (2013) se puede señalar que en la producción de conocimiento del Trabajo Social hay concepciones de pobreza de distintos matices. Constituye, por lo tanto, un escenario teórico con tendencias divergentes, convergentes, marcado por una "mezcla" teórico metodológico que se aproxima a un eclecticismo.

Este análisis no pretende ser clasificatorio ni se propone a etiquetar las concepciones. Se busca tan solo situar al lector sobre el campo en el que se sitúan los intelectuales y su alcance en el interior del Trabajo Social. En el caso de Carmelita Yasbek, Aldaisa Sposati, Maria Ozanira Silva y Vicente Faleiros, que son intelectuales del área de trabajo social los cuales tienen una enorme influencia en el ámbito de la profesión en lo que concierne a temas como pobreza, políticas sociales, asistencia social y derechos sociales. En el ámbito de la formación profesional en trabajo social las elaboraciones teóricas de estos intelectuales repercuten bastante a través de sus investigaciones y de su presencia en los principales periódicos del área de Trabajo Social. Se destaca en este escenario 
la investigadora Sônia Maria Fleury que aunque no sea del área de trabajo social es una intelectual bastante influyente en los debates de las ciencias sociales y humanas particularmente en los temas de democracia, control social, entre otros temas.

Robert Castel, Boaventura de Souza Santos y Antonny Giddens son intelectuales contemporáneos reconocidos y legitimados internacionalmente en diversas áreas de saber, los cuales traen nuevas reflexiones sobre los cambios sociales especialmente aquellas que alcanzan a la sociedad europea. Las ideas de articulación entre pobreza, vulnerabilidad, riesgo social presentes en sus análisis son fácilmente encontradas en las elaboraciones del Banco Mundial y Cepal. Estas nociones pueden ser identificadas también en la Política Nacional de Asistencia Social brasileña y por esta razón su influencia en el Trabajo Social puede ser significativa.

Un conjunto de intelectuales del porte de Amartya Sen y Deepa Narayan emergen en la actualidad con nuevas e inéditas elaboraciones que circulan globalmente con bastante proyección. En el caso de Amartya Sen su reconocimiento viene del premio nobel recibido en 1998 que proyecta su nombre para la academia, para las agencias gubernamentales y para las agencias multilaterales como Banco Mundial. Según Sen (2010) la pobreza puede ser comprendida como,

La pobreza debe ser vista como privación de capacidades básicas en lugar de meramente como bajo nivel de ingresos, que es el criterio tradicional de identificación de la pobreza. La perspectiva de la pobreza como privación de capacidades no implica ninguna negación de la idea razonable de que el bajo nivel de ingresos es claramente una de las causas principales de la pobreza, pues la falta de ingresos puede ser una razón primordial de la privación de capacidades de una persona (Sen, 2010, p. 120).

En una investigación realizada por Silva (2016) acerca de las iniciativas de enfrentamiento a la pobreza en América Latina se constata la predominancia de un concepto de pobreza centrado en el individuo, en sus capacidades y en las oportunidades a las que tiene acceso. La investigación de la autora indica que Amatya Sen es referencia en al menos tres países: Brasil, Uruguay y Argentina. Su influencia puede ser encontrada en las concepciones de libertad, de desarrollo, y en el abordaje multidimensional. En Brasil es emblemática su influencia en la PNAS, especialmente en programas sociales como Bolsa Familia -en el que actúan innumerables profesionales de Trabajo Social. La concepción de pobreza que fundamenta este programa se basa en la perspectiva multidimensional defendida por Amartya Sen. Es decir, en el referido programa social la pobreza es un fenómeno complejo, multidimensional caracterizado por la privación de capacidades individuales y de negación de oportunidades. A partir de este entendimiento los individuos deben ser habilitados para romper con el ciclo de pobreza generacional (Silva, 2016). Es válido resaltar que en esta óptica las cuestiones estructurales de la sociedad no son objeto de análisis ni de actuación del Estado y la dimensión económica es despreciada a la medida en que se entiende la pobreza como "privación de capacidades" individuales.

Ante estos elementos se indica la existencia de oposición entre las concepciones presentes en el ámbito de la formación profesional en Trabajo Social y aquellas que orientan la elaboración e implementación de políticas sociales, especialmente en la política de asistencia social. Las concepciones de pobreza predominantes en la formación 
profesional en Trabajo Social son masivamente influenciadas por las matrices afiliadas a la tradición marxista, en la que prevalecen la perspectiva de totalidad y el método materialista histórico ${ }^{8}$, los cuales consisten en la dirección teórico-metodológica del proyecto de Formación Profesional desde la década de 1980.

Las concepciones presentes en la PNAS, LOAS, en el programa Bolsa Familia entre otros, son influenciadas por las concepciones de intelectuales como Amartya Sen, las cuales no reconocen la dimensión estructural de los fenómenos que generan la pobreza. Aunque sean visiones contrastantes estas concepciones han sido relevantes en la elaboración de las concepciones y de los discursos de parte de los profesionales de Trabajo Social, sobre todo aquellos que actúan en el área de la asistencia social y que se enfrentan con las expresiones de la pobreza y con una población pauperizada.

Se retoma aquí la tesis defendida en esta publicación, que el debate sobre la pobreza se profundiza en el Trabajo Social a partir de los años 2004, cuando la Promulgación de la Política Nacional de Asistencia Social trae a la luz polémicas teórico-metodológicas en torno a las concepciones de pobreza e indica polarizaciones teóricas consistentes.

Así, ante las principales tendencias teóricas que influencian la producción de conocimiento y la Formación Profesional en Trabajo Social es posible identificar que hay una "mezcla" de concepciones formado por aportes de la matriz marxista que explican la pobreza a partir de la Ley General de la Acumulación y que estas tendencias se encuentran de lado a lado, con aportes teóricos anclados en perspectivas liberales en las que los análisis privilegian la esfera política de las relaciones en sociedad.

De esta forma, nociones de vulnerabilidad, riesgo social, capacidades, oportunidades, condicionalidades y la perspectiva de empoderamiento son ejemplos de estas influencias teórico-metodológicas de cariz liberal. Así, se concluye que, aunque haya en el ámbito de la formación profesional el predominio de concepciones de pobreza afiliadas a la tradición marxista, coexisten en la producción de conocimientos y en las políticas y programas sociales algunas concepciones de pobreza afiliadas a matrices teórico-metodológicas oponentes y críticas a la perspectiva crítica-dialéctica, configurando un cuadro analítico marcado por el eclecticismo teórico metodológico en relación con esta temática.

La presencia de estas perspectivas opuestas genera polémicas teóricas que se expresan en la formación profesional de los trabajadores sociales, en la producción teórica de los autores y también en la actuación de los profesionales de Trabajo Social, teniendo en cuenta que actúan en los programas sociales gubernamentales y, de esta forma, son guiados por las directrices y principios filosóficos de dichos programas.

Ante estos elementos, se considera útil recurrir a una concepción de pobreza que pueda aprehender los fundamentos estructurales de este fenómeno y que sea capaz de asociar los determinantes económicos, articulándolos a los elementos de la cultura,

8 En términos históricos los análisis sobre el Trabajo Social desde una perspectiva de totalidad se remiten al proceso Renovación del Trabajo Social. Este proceso culmina en una revisión crítica sobre la actuación profesional del Trabajador Social, incluyendo la revisión de sus aportes teóricos, marcadamente en la década de 1970. A lo largo de los años 1980 y 90 la profesión pasa a revisar su proyecto de formación profesional. Así, Como uno de los resultados del movimiento de Renovación del Trabajo Social se destaca la revisión curricular que ocurre en la década de 1990, que da origen a las Directrices Curriculares para el Curso de Trabajo Social, aprobadas por el Ministerio de Educación y Cultura en el año 1996. A partir de este momento la formación profesional apunta como perspectiva primordial un análisis riguroso de los aspectos teóricos, históricos y metodológicos de la realidad social anclada en una teoría social crítica y en un método materialista, histórico y una visión de totalidad de las relaciones sociales. Un marco en este proceso de reformulación de las bases profesionales es la afirmación del estatuto profesional del Trabajo Social definido como una especialización del trabajo colectivo en los marcos del capitalismo monopolista (Iamamoto, 2008). 
Andrade-da-Silva - Pobreza en la producción de conocimiento y la formación profesional del Trabajo Social en Brasil

de la política, de la subjetividad y de la visión de mundo de los sujetos. Es decir, una comprensión de pobreza que no genera polarizaciones entre económico/político, sino que ayude a aprehender los fundamentos, las contradicciones y las expresiones ampliadas del fenómeno pobreza en la actualidad.

En esa perspectiva se adopta la síntesis elaborada por Silva (2016) a través de la cual la pobreza puede ser comprendida a partir de una visión de totalidad y de un abordaje estructural. La autora inicialmente define pobreza como una manifestación de la cuestión social y se deriva del cuadro de desigualdad social y de la consecuente concentración de renta en Brasil. Puede ser definida:

Como un proceso estructural, complejo, de naturaleza multidimensional, relativo, no pudiendo ser considerado como mera insuficiencia de renta; es también desigualdad en la distribución de la riqueza socialmente producida; es no tener acceso a servicios básicos; a la información; al trabajo y a una renta digna; es la no participación social y política (Silva, 2016, p. 95).

Aunque se considera que el abordaje multidimensional de Amartya Sen es un avance en relación con las tradicionales definiciones de pobreza por el sesgo monetario es necesario puntuar que la propuesta de entender el carácter multidimensional de la pobreza no significa lo mismo que comprenderla desde una perspectiva de totalidad. El autor teje críticas consistentes a los análisis economicistas y propone un abordaje que, aunque defienda la multimensionalidad, termina por naturalizar la pobreza y culpar al individuo por su condición social. En este sentido, este enfoque recupera rasgos de las tradicionales lecturas sobre pobreza y sobre las formas de actuación con poblaciones pobres marcadas por acciones de control y castigo y culpabilización.

\section{CONCLUSIONES}

Al final de este artículo conviene presentar alguna síntesis. Tal tarea exige que se retome la tesis que se defendió y que orientó los análisis realizados. Se defiende la tesis que el debate sobre la categoría pobreza se profundiza en el Trabajo Social a partir de los años 2004, cuando la Promulgación de la Política Nacional de Asistencia Social trae a la luz polémicas teórico-metodológicas en torno a las concepciones de pobreza. A partir de este período el mercado de trabajo para las trabajadoras sociales en el ámbito de esta política se amplía, resultando no solo en nuevas inserciones profesionales, sino en el embate de las concepciones de pobreza en curso. Este escenario trae a la superficie algunas polémicas teóricas relevantes en el ámbito de la formación profesional y de la producción de conocimientos en el área de Trabajo Social. Las expresiones de la relevancia del debate sobre pobreza también pueden ser identificadas en los encuentros nacionales de mayor relevancia en el país. A título de ilustración en los últimos Congresos Brasileño de Trabajadoras Sociales y en los Encuentros Nacionales de Investigadores es posible encontrar innumerables artículos en los cuales se analizaban aspectos relativos a la pobreza. Lo que indica que en la producción de conocimientos el tema pobreza es una preocupación de los investigadores.

Es necesario considerar que el debate involucrando las concepciones de pobreza ocurre en un escenario de intensa mercantilización de la enseñanza superior brasileña cuyas características marcadas son un tipo de enseñanza aligerada, productivista, tecnicista, 
empirista y restringido a las demandas inmediatas del mercado de trabajo y que, en términos generales, se vuelve al entrenamiento de competencias operativas en los profesionales (Guerra, 2013).

Así, los cambios surgidos de la implementación de la PNAS/SUAS en el contexto de crisis del capital lanzan a la formación profesional algunos desafíos de gran importancia. Se destacan los siguientes:

a) Mantener la calidad de la formación en un contexto de aligeramiento y precarización de la enseñanza pública y de mercantilización de la educación superior;

b) La PNAS/SUAS ha generado para la actuación de las Trabajadoras Sociales requisiciones de conocimiento de la realidad con énfasis en los elementos de orden técnico-operativa que pueden resumir la actuación del profesional al entrenamiento y al "saber hacer";

c) Mantener la capacidad de conocer lo real sin limitar a los fragmentos de la Cuestión Social reafirmando una de las características de la formación profesional que es la creación de un perfil profesional generalista capaz de interpretar la cuestión social y actuar sobre sus efectos;

d) Articulación entre las dimensiones de la práctica profesional (ética, política, teórica, técnico-operativa) que involucra distintas competencias por parte de los profesionales (ejecutiva, pero también investigativa, de formulación, monitoreo, así como de evaluación y planificación de procesos, programas y acciones);

e) Por último, llama la atención sobre un desafío de gran magnitud: la comprensión por parte de los/las trabajadoras sociales de los límites de las políticas para enfrentar la pobreza.

Esto porque la implementación de los PTR's incrementó el mercado de trabajo de los trabajadores sociales generando alta demanda por contratación de esos profesionales. Sin embargo, cabe entender los límites de esas iniciativas y el papel de la asistencia social en tiempos de crisis del capital y de ofensiva sobre los trabajadores. Las iniciativas de Asistencia Social implementadas en el marco de las estrategias de combate a la pobreza se constituyen como acciones de carácter temporal y que se enfocan en segmentos específicos considerados como "vulnerables", cuya medición de los niveles de pobreza se define a partir de la insuficiencia de ingresos.

Ante estos elementos, cabe reiterar que la pobreza posee determinaciones de amplio espectro social e histórico y que su enfrentamiento demanda considerar la cuestión del descarte de la mano de obra barata en el interior de los procesos de expansión del capital. En estos términos se consideran estrategias que, aunque avancen en la perspectiva de superación de la pobreza, no alcanzan las desigualdades sociales, pues sus efectos todavía permanecerán por largos períodos de la historia de Brasil y Latinoamérica. Este análisis solo es posible en la medida en que la concepción sea anclada en una perspectiva de totalidad en la cual las determinaciones de la pobreza puedan ser desveladas para identificar los límites de las estrategias en la esfera de la cultura y de la política en detrimento de alteraciones en las relaciones económicas que rigen la sociedad. En consonancia con Yasbek (2012) se afirma que es necesario: 
Integrar las políticas de enfrentamiento a la pobreza con políticas universales una combinación adecuada entre las llamadas políticas estructurales orientadas a la redistribución de la renta, el crecimiento de la producción, la generación de empleos, la reforma agraria, entre otros y la intervención de orden de emergencia, a menudo llamadas políticas compensatorias. Limitarse a estas últimas cuando las políticas estructurales siguen generando desempleo, concentrando la renta y ampliando la pobreza..., significa desperdiciar recursos, engañar a la sociedad y perpetuar el problema (p. 318).

En términos analíticos, se parte del presupuesto de que la pobreza no se reduce a privaciones materiales y puede ser considerada una categoría multifactorial, pero es necesario identificar que el momento económico es determinante en el establecimiento de las relaciones fundantes en la sociedad burguesa. Así, se considera la propuesta de Amartya Sen teóricamente insuficiente, pudiendo llevar a análisis moralizadores y culpables de la pobreza. Se adoptan aquí las reflexiones de Yasbek (2012) que inicia sus análisis afirmando que la pobreza se revela como una cara del descarte de mano de obra, fenómeno resultante de las formas de expansión de la economía capitalista. También se considera adecuada la síntesis de Silva (2016) y su abordaje histórico, multidimensional bajo una óptica de totalidad para explicar la pobreza y sus consecuencias.

Así, se comprende que la formación profesional en Trabajo Social supone la construcción de sujetos cívicos y políticos aptos que se insertan en los diversos movimientos sociales de la sociedad y actúa en el interior de sus contradicciones. En este escenario, los desafíos para la formación profesional se agudizan en lo que concierne garantizar la calidad de la enseñanza que posibilite a los sujetos descifrar lo real a través de la investigación de fenómenos y de la calificación teórica de los procesos y de las categorías teóricas. En este sentido, la presencia del eclecticismo teórico es generadora de impasses (teóricos y prácticos) poniendo en un mismo campo nociones teóricas excluyentes que inversamente ofuscan la realidad en lugar de descifrarla. El discurso de la "complementariedad" de las teorías no se valida en la realidad, teniendo en cuenta que los abordajes identificados tienden a excluirse y no complementarse. En ese sentido, es necesario adensar las investigaciones en torno a la pobreza para dejar claras las divergencias teóricas existentes en el sentido de clarificar las tendencias existentes y superar el eclecticismo. Por último, se considera que aunque la tarea es hercúlea, la masa crítica de la categoría de trabajadores sociales ha trabajado incesantemente para auxiliar a la categoría profesional en la lectura del real.

\section{REFERENCIAS}

ABESS/CEDEPSS (1996). Propuesta básica para el proyecto de formación profesional. In: Revista Serviço Social e Sociedade, (50).

Amman, S. B. (2013). Expresiones de la pobreza en Brasil: análisis a partir de las desigualdades regionales. SP: Cortez.

Brasil (2004). Política Nacional de Asistencia Social. Ministerio de Desarrollo Social y Combate a la Pobreza: Brasília. 
Guerra, Y. D. (2013). Formación profesional en el Trabajo social: polémicas y desafíos. In: Silva, J. F. S.; Sant'Ana, R. S.; Lourenço, E. A. S (org). Sociabilidad burguesa y trabajo social. RJ: Editora Lumens Juris.

Iamamoto, M. V. (2008). Trabajo social en tiempos de capital fetiche: capital financiero, trabajo y cuestión social. SP: Cortez.

Martinelli, M. L. (2011). Trabajo Social: Identidad y enajenación. SP: Cortez.

Mota, A. E.; Maranhão, C. H.; Sitcovsky, M. (2008.) Las tendencias de la política de asistencia social, el sistema único de asistencia social y la formación profesional. En: el mito de la asistencia social: ensayos sobre Estado, política y sociedad. Mota, A. E. (org). (2. ed.). SP: Cortez.

Sem, A. (2010). Desarrollo como libertad. Tradução Laura Teixeira Motta. SP: Companhia das Letras.

Silva, M. O. S. (2016). Pobreza y políticas de enfrentamiento a la pobreza / Organizadora Maria Ozanira da Silva e Silva - São Luís: EDUFMA.

Silva, E. A.; Domingos, M. (2017). Las representaciones sociales de los cursistas de la Iniciativa Educación, Pobreza y Desigualdad Social sobre la pobreza. Relatório de Pesquisa. Natal. Mimeo.

Siqueira, L. (2013). Pobreza y Trabajo social: diferentes concepciones y compromisos políticos. SP: Cortez

Telles, V. S. (2013). Pobreza y ciudadanía. SP: Programa de Pós Graduação em Sociologia da FFLCH-USP/editora 34, (2a ed).

Yasbek, M. C. (2012). Pobreza en el Brasil contemporáneo y formas de enfrentamiento. In: Revista Serviço Social e Sociedade, 110. 